\title{
Features of physical development and somatotype of girls and women involved in fitness
}

\author{
Podrigalo L.V. ${ }^{1,3 \mathrm{ABCD}}$, Artemieva H.P. ${ }^{2 \mathrm{ABCD}}$, Rovnaya O.A. ${ }^{1 \mathrm{ABCD}}$, Misevra N.S. ${ }^{2 A B C D}$, Sotnikova-Meleshkina Zh.V. ${ }^{3 \mathrm{ABCDE}}$, \\ Podavalenko A.P. ${ }^{4 A B C D E}$, Sokol K.M. ${ }^{5 A B C D E}$, Robak I.Yu. ${ }^{6 A B C D E}$ \\ ${ }^{1}$ Department Hygiene and Human Physiology, Kharkov State Academy of Physical Culture, Ukraine \\ ${ }^{2}$ Department of Dance Sports, Fitness and Gymnastics, Kharkov State Academy of Physical Culture, Ukraine \\ ${ }^{3}$ Department Hygiene and Social Medicine, V. N. Karazin Kharkov National University, Ukraine \\ ${ }^{4}$ Department of Hygiene, Epidemiology and Occupational Diseases, Kharkov Medical Academy of Postgraduate \\ Education, Ukraine \\ ${ }^{5}$ Department Hygiene and Social Medicine, Kharkov National Medical University, Ukraine \\ ${ }^{6}$ Department of Social Sciences, Kharkov National Medical University, Kharkov, Ukraine
}

Authors' Contribution: A - Study design; B - Data collection; C - Statistical analysis; D - Manuscript Preparation; E - Funds Collection.

\begin{abstract}
Purpose:

Comparative analysis of the physical development features and somatotype of girls and women involved in fitness.

Material:

The experiment involved 95 girls and women, divided into 2 groups. Group 1 - 48 girls (36.04 \pm 0.19$)$ years, Group $2-47$ women $(43.26 \pm 0.22)$ years, $(p<0.01)$. Participants practiced fitness $2-3$ times a week. The duration of the training was 60 minutes. It was determined the body mass and body length, wrist circumference, waist and hips circumferences. The TANITA BC 587 analyzer was applied to determine muscle and fat mass, the specific weight of fat tissue, water content, percentage of visceral fat, basal metabolism value, bone mass mineralization. It was calculated the body mass index and the waist-tohip ratio. The results were evaluated applying the Student's t-test $(\mathrm{t})$ and Rosenbaum $(\mathrm{Q})$ and Wilcoxon - Mann - Whitney (U) criteria.

Results: $\quad$ There were no significant differences in body length and body mass. The girls confirmed a less value of hip circumference $(t=2.04, p<0.05)$ and a tendency to less waist circumference $(t=1.97, p<0.1)$ in comparison with group 2. The participants of group 2 had a larger wrist circumference $(U=891, p<0.05)$. According to this parameter, persons with asthenic body type prevailed among participants. Their specific weight was $(56.25 \pm 7.16) \%$ of group 1 and $(53.19 \pm 7.28) \%$ of group 2 . It was confirmed less absolute body fat content in group $1(\mathrm{t}=2.09, \mathrm{p}<0.05)$. All participants were characterized by larger muscle mass. There were no differences in this parameter between groups. It was determined the high concentration of specific weight of fat tissue in comparison with age standards. The content of visceral fat was within the age norm. Its content was higher in group $2(Q=18, p<0.01)$. The basal metabolic value was larger in group $2(Q=17, p<0.01)$. The values of bone mass mineralization reflect the correspondence to the body mass of the participants. This parameter did not have significant differences in the groups. The body mass index value in group 1 was within the average interval. In group 2, this index was higher than the standard one. The body mass index in group 1 was significantly lower $(t=2.18, p<0.05)$. The participants with a body mass index above the norm were $(35.42 \pm 6.90) \%$ of group 1 and $(59.57 \pm 7.16) \%$ of group 2. The prevalence of waist-to-hip ratio above the norm was $(54.17 \pm 7.19) \% 1$ group and $(59.57 \pm 7.17) \%$ 2 group, $(p>0.05)$.

Conclusions: $\quad$ it was determined the proximity of the main anthropometric parameters (mass and body length). The girls have lower values of the hip circumference. Persons with asthenic body type prevailed among the participants. Analysis of the indices confirmed the high prevalence of overweight and high risk of developing metabolic syndrome. The application of bio-impedance method confirmed and clarified the results of anthropometric research. The participants demonstrated the increased content of subcutaneous and visceral fat, increasing with age. The water level in the body gradually decreases with age. This is considered as a reflection of age-related physiological changes in metabolism and should be considered in fitness training organizing. Studies have confirmed the informativeness and adequacy of the bio-impedance method.

Keywords: $\quad$ physical development, somatotype, bio-impedance method, fitness.
\end{abstract}

\section{Introduction}

The main goal of the recreational physical culture classes is to optimize the students' health condition by improving the physique appearance and body shape. Evaluation of training effectiveness determines the (c) Podrigalo L.V., Artemieva H.P., Rovnaya O.A.,

Misevra N.S., Sotnikova-Meleshkina Zh.V.,

Podavalenko A.P., Sokol K.M., Robak I.Yu., 2019

doi:10.15561/18189172.2019.0405 implementation of this goal. The most informative and accessible assessment criterion in this context is the dynamics of physical development indicators (level and harmony, biological age, human body composition).

Components of the somatotype are widely applied in science as criteria for human health. Tan et al. [1] estimated the type of lifestyle on the content of fat and muscle tissue in the body. 
Schubert et al. [2] emphasize that body composition measurements are necessary for performance analysis in health monitoring. These methods must be accurate, practical and minimally invasive. It was confirmed the information content and reliability of the bio-impedance method.

Koury et al. [3] evaluated the effect of biological maturity on body composition in Brazilian adolescents. It was confirmed the information content of the bioimpedance method. It is recommended to consider sexual (female) or skeletal (male) maturity in evaluating body composition.

Gavryushin et al. [4] used body composition as a criterion for the effectiveness of summer recovery. Bioimpedance method confirms the results of anthropometric measurements, provides information about the diet for children, the level of physical activity.

Ez-López et al. [5] used the bio-impedance method as a criterion for assessing the physical activity of children and adolescents.

In a review of Castizo-Olier et al. [6] was studied the usefulness and suitability of the bio-impedance method for assessing body composition, hydration status, and other physiological and clinical significant characteristics. It emphasizes the need for research that establishes standardized testing procedures and examines the relationship between physiology and the bioelectric signal in sport and exercise.

Mundi et al. [7] analyzed the most common technologies for assessing body composition (bioimpedance, computed tomography, and ultrasound). The review highlights the advantages and disadvantages of each method. Assessment of body composition applying new methods provides a unique opportunity to develop improved methods for assessing the risk of nutrition based on objective data.

Nickerson et al. [8] evaluated the validity of field and laboratory methods for assessing body composition in healthy adults. The error values were the smallest in the bio-impedance method. Authors recommend the widespread application of this method.

Bastawrous et al. [9] applied the bio-impedance method to assess the physical development of adults in Kenya. The authors developed centile reference curves for the mass without fat and the mass of fat, taking into account height, age and sex.

Mascherini et al. [10] used the bioimpedance method to establish differences in the adaptive capacity of the heart in men and women. It is concluded that the ability of the heart to adapt to physical stress depends on body composition.

Ramos-Jimenez et al. [11] applied the bio-impedance method to develop anthropometric equations for calculating fat in the body of young people. It was confirmed the coincidence of data obtained applying bioimpedance and densitometry.

Bacciotti et al. [12] evaluated the physical characteristics of the Brazilian gymnasts of various skill levels. It was determined the similarity of anthropometric characteristics. Non-elite gymnasts had high fat levels. Within the same age groups, the similarity of profiles was confirmed regardless of the skill level.

The results of the bio-impedance method and the reference methods are compared for assessing body composition in a review of Chula de Castro et al. [13]. It was confirmed the high reproducibility of determining the percentage of fat, fat mass, and fat-free mass.

Thus, the available results testify to the high information content and adequacy of the bio-impedance method in monitoring the status of athletes and nonathletes.

Based on the above mentioned, the purpose of the study was a comparative analysis of the characteristics of physical development and the somatotype of girls and women involved in fitness.

\section{Materials and methods}

Participants.

The study involved 95 girls and women, divided into groups according to age. Group 1 includes 48 girls, the average age was $(36.04 \pm 0.19)$ years. Group 2 includes 47 women, the average age was $(43.26 \pm 0.22)$ years, ( $\mathrm{p}<0.01)$. Participants practiced fitness 2-3 times a week. The duration of the training was 60 minutes. All participants gave informed consent to participate in the study.

\section{Design of the study}

The design of the study involved the determination of anthropometric indicators, the calculation of physical development indices using special formulas, the determination of the components of the somatotype by the bio-impedance method.

The determination of the body mass and body length, wrist, waist and hip circumference was carried out in accordance with international standards [14].

The wrist circumference within $16-18 \mathrm{~cm}$ was estimated as an indicator of the normostenic body type. The indicator less than $16 \mathrm{~cm}$ testified about the asthenic body type, more than $18 \mathrm{~cm}$ testified about the hypersthenic body type.

The bio-impedance method was applied to evaluate the somatotype. It was applied a body composition monitor TANITA BC 587 (Japan). It was determined the muscle and fat mass, specific weight of fat tissue, water content, percentage of visceral fat, basal metabolic value, bone mass mineralization.

The calculation of body mass index (BMI) is carried out according to the formula:

$$
\mathrm{BMI}=\mathrm{BM} / \mathrm{BL} 2(1) \text {, }
$$

where BMI is the body mass index, $\mathrm{kg} / \mathrm{m}^{2}, \mathrm{BM}$ is the body mass $(\mathrm{kg}), \mathrm{BL}$ is the body length $(\mathrm{m})$.

The norm value is $19-24 \mathrm{~kg} / \mathrm{m}^{2}$

The waist-to-hip ratio (WHR) was calculated as a ratio of these circumferences. The index value more than 0.85 was estimated as obesity according to the recommendations of the World Health Organization. 
Statistical analysis

Statistical analysis of the results was carried out with licensed MS Excel. Indicators of descriptive statistics were determined: arithmetic mean, standard deviation and error of mean value. In relative indicators were determined the prevalence of the indicator and its error. The significance of differences in the groups was assessed by Student's t (t), Rosenbaum (Q), and Wilcoxon-MannWhitney (U) criteria.

\section{Results.}

The results are shown in table 1 .

It was determined the proximity of the main anthropometric parameters of the participants. There were no significant differences in length and body mass.

At the same time, certain differences in physical development and the state of the somatotype were revealed. The girls confirmed a smaller hip circumference $(\mathrm{t}=2.04, \mathrm{p}<0.05)$ and a tendency to a smaller waist circumference $(\mathrm{t}=1.97, \mathrm{p}<0.1)$ compared with group 2 .

The participants in group 2 had a large wrist circumference $(U=891, p<0.05)$. Persons with asthenic body type prevailed among them according to this parameter. Their specific weight was $(56.25 \pm 7.16) \%$ of group 1 and $(53.19 \pm 7.28) \%$ of group 2, $(\mathrm{p}>0.05)$. There were no participants with a hypersthenic body type in group 1 , in group $2-(2.13 \pm 2.10) \%$.

It was confirmed the lower level of absolute body fat content in group $1,(\mathrm{t}=2.09, \mathrm{p}<0.05)$.

All participants were characterized by relatively large values of muscle mass in comparison with age norms. There were no differences in this parameter between groups.

The specific weight of fat tissue reflects its increased content compared to age standards. At the same time, the visceral fat content was within the age norm. The amount of visceral fat was higher in group $2(\mathrm{Q}=18, \mathrm{p}<0.01)$.

Comparison of the specific weight of water also indirectly confirms the participants' overweight. The amount of water was higher in group $1(\mathrm{Q}=7, \mathrm{p}<0.05)$.

Basal metabolism value was higher in group $2(\mathrm{Q}=$ $17, \mathrm{p}<0.01)$.

The values of bone mass mineralization reflect the correspondence to the body mass of the participants. There weren't significant differences in the groups.

The body mass index value in group 1 was within the average interval. This index was higher than the standard in group 2 . The body mass index in group 1 was significantly lower $(\mathrm{t}=2.18, \mathrm{p}<0.05)$. Interesting data was obtained by analyzing the structure of the calculated indices. The body mass index less than 19 had $(4.17 \pm$ $2.88) \%$ of participants in group 1 and $(2.13 \pm 2.10) \%$ of group $2,(p>0.05)$. The number of participants with a body mass index above the norm was significantly higher. In group 1 , their share was $(35.42 \pm 6.90) \%$, in group $2-$ $(59.57 \pm 7.16) \%,(\mathrm{t}=2.43, \mathrm{p}<0.05)$.

The prevalence of WHR above normal was $(54.17 \pm$ $7.19) \%$ of group 1 and $(59.57 \pm 7.17) \%$ of group 2 , $(\mathrm{p}>$ $0.05)$.

Table 1. Indicators of physical development and somatotype of girls and women involved in fitness

\begin{tabular}{lll}
\hline Indicator & $\mathbf{1}$ group & $\mathbf{2}$ group \\
\hline Body length, $\mathrm{m}$ & $1.68 \pm 0.01$ & $1.67 \pm 0.01$ \\
Body mass, kg & $66.65 \pm 1.53$ & $69.83 \pm 1.43$ \\
The specific weight of fat tissue, \% & $30.38 \pm 6.64$ & $33.94 \pm 6.91$ \\
The amount of fat, kg & $20.89 \pm 1.14^{1}$ & $24.19 \pm 1.10$ \\
The specific weight of visceral fat, c.u. & $3.71 \pm 2.73$ & $5.96 \pm 3.45$ \\
Muscle mass, kg & $43.49 \pm 0.47$ & $43.36 \pm 0.47$ \\
The specific weight of water, \% & $48.81 \pm 7.21$ & $46.48 \pm 7.28$ \\
Bone mass mineralization, $\mathrm{kg}$ & $2.36 \pm 0.03$ & $2.30 \pm 0.02$ \\
Basal metabolism value, kcal & $1366.38 \pm 15.30$ & $1379.82 \pm 27.83$ \\
Wrist circumference, cm & $15.65 \pm 0.14$ & $15.95 \pm 0.14$ \\
Waist circumference, cm & $85.13 \pm 1.16^{2}$ & $88.50 \pm 1.25$ \\
Hip circumference, $\mathrm{cm}$ & $99.19 \pm 0.83^{1}$ & $101.48 \pm 0.76$ \\
The waist-to-hip ratio, c.u. & $0.86 \pm 0.01$ & $0.87 \pm 0.01$ \\
Body mass index, $\mathrm{kg} / \mathrm{m}^{2}$ & $23.44 \pm 0.53^{1}$ & $24.99 \pm 0.47$ \\
\hline
\end{tabular}

Notes. 1 - the differences are significant $(p<0.05), 2$ - the tendency to significance $(p<0.1)$. 


\section{Discussion}

The accomplishment of the set goal - the effectiveness assessment of the recreational physical culture training requires the use of informative tests and methods in the monitoring of students' status. The main criteria for their choice are the specificity of the loads and training features.

Thus, in synchronized swimming, the most informative methods evaluate the functional state of the respiratory system [15]. The application of psychophysiological and biochemical tests is effective in martial arts $[16,17,18]$.

The assessment of the characteristics of physical development and somatotype is the most adequate in fitness. This determined the choice of battery methods for research.

The division of participants by age allows: to assess more accurately the impact of loads on the body; to consider the physiological age-related changes in classes' organizing; predict the dynamics of the main criteria. Such design was applied in the work of de-MateoSilleras et al. [nineteen]. The authors determined the main anthropometric parameters and components of the somatotype applying the bioimpedance method. It is concluded that it is possible to predict metabolic risks according to the obtained data. This basically coincides with the set goal in this study.

The absence of significant differences in length and body mass should be assessed as the proximity of the physical development of the participants, confirming the validity of the choice of these age groups for comparative analysis.

The results of the comparison of waist and hip circumferences reflect the physiological features of the participants. In the older group there is a gradual change in metabolism, slowing its intensity. This leads to an increase in fat deposition in problem areas - at the waist and hips. The obtained results require clarification using body composition analysis.

The similar results are reported in Tinsley et al. study [20]. The authors conducted a comparative analysis of the effectiveness of athletes' body composition assessing methods. There were differences in fat mass in men and women. These results may be important for optimal methods for assessing body composition with atypical body characteristics.

The average values of the wrist circumference belonged to the interval of asthenic body type. The predominance of this type of constitution is confirmed by the analysis of the structure of the parameter. Perhaps the larger average values in group 2 are due to age-related changes in physical development.

The increase in muscle mass compared with age norms is the result of regular fitness training. This confirms the adequacy of the choice of body composition analysis to assess the effectiveness of training.

Comparison of the content of subcutaneous and visceral fat again confirms the assumption of overweight participants. The increase in mass is due to the increase in the specific weight of subcutaneous fat. This should be evaluated as a risk factor for the development of chronic non-communicable diseases. The determined features of the somatotype should be considered in fitness training organizing.

The obtained results illustrate the significance of the somatotype evaluating and the fat component determining in condition monitoring the persons involved in fitness. Branco et al. [21] emphasize that determining the percentage of body fat in a person's body makes it possible to assess health at a population level or determine the level of risk. The authors developed centile tables of fat content depending on the level of physical activity.

The common results were obtained by van Rassel et al. [22]. The authors conducted a comparative analysis of the fat content in individuals with different body mass. It was defined that the error of the bio-impedance method is minimal in normal mass and increases with obesity.

The application of the index method in the analysis of physical development is due to their simplicity, accessibility, and information. The available information allows to recommend physical development indexes as screening tests in monitoring the athletes' status.

Analysis of body mass index and the content of subcutaneous and visceral fat confirms previously made assumptions about a decrease in the intensity of metabolism. The probability of overweight due to an increase in a fat deposition is significantly higher in older participants. This allows to conclude about the need for a differentiated approach in the organization of recreational activities.

At the same time, the results of the body mass index have a rather high error. They need to be supplemented with a somatotype analysis. De-Mateo-Silleras et al. [23] determine that bioelectric impedance analysis (BIA) is a more accurate body composition analysis method than body mass index. The results of the bio-impedance method allow to diagnose obesity more accurately than the body mass index.

Filatova and Voronina [24] compared the sensitivity of body mass index and the results of the bio-impedance method for the diagnosis of obesity in adolescents and young people. The low sensitivity of the indices was confirmed in comparison with the bio-impedance method.

In the work of Araujo et al. [25] emphasizes the necessity of population-based methods for determining body fat. These methods must be accurate, reliable and low cost. Body fat was measured by bioelectric impedance analysis. The level above the average was considered above $16 \%$ for men and above $24 \%$ for women. The BMI value with the best balance between sensitivity and specificity was $22 \mathrm{~kg} / \mathrm{m} 2$ and $23 \mathrm{~kg} / \mathrm{m} 2$ for women and men, respectively. The data presented by the authors coincide with the obtained results and with our conclusions.

Analysis of the obtained results allows to recommend a set of used indicators and indices for condition monitoring the persons involved in fitness. This confirms the available literature data. The use of bio-impedance method allowed to significantly expand the data obtained in the analysis of body mass index. Thus, our results coincide with the data 
of Girsh and Gerasimchik [26]. The authors emphasize the promising application of the bio-impedance method in sports medicine, its advantages over the definition of body mass index.

Interesting data were obtained in the comparison of the water content in the body. In our opinion, its decrease in group 2 illustrates age-related changes in moisture saturation of the organism due to changes in metabolism.

Campa at al. [27] determined the volleyball player profile by body composition parameters. It was determined the dependence of the somatotype on the skill level. Elite athletes had more fat-free mass (FFM) and total body water (TBW), as well as less fat mass (FM).

Chatindiara et al. [28] studied the correlations between nutritional risk, body composition, and the physical activity of New Zealand residents. It was determined the correlations between the fat-free mass (FFM) and the percentage of body fat and indicators of physical activity.

Analysis of the body mass index structure once again confirms the assumption about the overweight of the majority of participants. If in 1 group of such girls there was a little more than $30 \%$, then in group 2 - almost $60 \%$. In our opinion, this once again illustrates the position of age-related changes in metabolism and an increase in the possibility of fat deposition.

A similar conclusion allows to make a comparative analysis of WHR. More than $50 \%$ of the participants had a value of this index above the norm. This should be considered as a risk factor for the development of the metabolic syndrome. And this condition is a prerequisite for the development of many chronic non-communicable diseases.
Similar results were reported by Fedewa et al. [29]. The authors studied the relationship between anthropometric indicators and indices, their predictive value. It was determined the percentage of body fat. It was determined that waist circumference and fat index are more closely related to this parameter than body mass index.

\section{Conclusions}

The comparative analysis established the features of physical development and the somatotype of girls and women involved in fitness. It was determined the proximity of the main anthropometric parameters (mass and body length). At the same time, girls demonstrated the lower values of hips circumference. Persons with asthenic body type prevailed among the participants. The application of bio-impedance method confirmed and clarified the obtained results. The participants had increased content of subcutaneous and visceral fat, increasing with age. The water level in the body gradually decreases with age. This is considered as a reflection of age-related physiological changes in metabolism and should be considered in fitness training organizing.

The carried out studies once again confirmed the informativeness and adequacy of the bio-impedance method. This method in the complex with the index method should be applied in the condition monitoring of girls and women involved in fitness.

\section{Conflict of interest}

The authors declare that there is no conflict of interest.

\section{References}

1. Tan X, Titova OE, Lindberg E, Elmståhl S, Lind L, Schiöth $\mathrm{HB}$, et al. Association Between Self-Reported Sleep Duration and Body Composition in Middle-Aged and Older Adults. Journal of Clinical Sleep Medicine, 2019;15:431-5. https://doi.org/10.5664/jcsm.7668

2. Schubert MM, Seay RF, Spain KK, Clarke HE, Taylor JK. Reliability and validity of various laboratory methods of body composition assessment in young adults. Clinical Physiology and Functional Imaging, 2019;39:150-9. https://doi.org/10.1111/cpf. 12550

3. Koury JC, Ribeiro MA, Massarani FA, Vieira F, Marini E. Fat-free mass in adolescent athletes: Accuracy of bioimpedance equations and identification of new predictive equations. Nutrition, 2019;60:59-65. https://doi.org/10.1016/j.nut.2018.09.029

4. Gavryushin My, Sazonova O, Gorbachev D, Borodina L, Frolova O, Tupikova D. A rationale for the use of anthropometric measurements and bioelectrical impedance analysis as efficacy criteria for summer camp healthcare. Bulletin of Russian State Medical University, 2019:89-95. https://doi.org/10.24075/brsmu.2019.024

5. Sánchez-López M, Ruiz-Hermosa A, Redondo-Tébar A, Visier-Alfonso ME, Jimenez-López E, et al. Rationale and methods of the MOVI-da10! Study -a cluster-randomized controlled trial of the impact of classroom-based physical activity programs on children's adiposity, cognition and motor competence. BMC Public Health, 2019;19. https://doi.org/10.1186/s12889-019-6742-0

6. Castizo-Olier J, Irurtia A, Jemni M, Carrasco-Marginet M, Fernández-García R, Rodríguez FA. Bioelectrical impedance vector analysis (BIVA) in sport and exercise: Systematic review and future perspectives. Plos One, 2018;13:e197957. https://doi.org/10.1371/journal.pone.0197957

7. Mundi MS, Patel JJ, Martindale R. Body Composition Technology: Implications for the ICU. Nutrition in Clinical Practice. 2019; 34(1): 48-58. https://doi.org/10.1002/ncp.10230

8. Nickerson BS, Tinsley GM, Esco MR. Validity of Field and Laboratory Three-Compartment Models in Healthy Adults. Medicine and Science in Sports and Exercise, 2019; 5: 1032-1039. https://doi.org/10.1249/MSS.0000000000001876

9. Bastawrous MC, Piernas C, Bastawrous A, Oke J, Lasserson D, Mathenge W, et al. Reference values for body composition and associations with blood pressure in Kenyan adults aged $\geq 50$ years old. European Journal of Clinical Nutrition, 2019;73:558-65. https://doi.org/10.1038/s41430-018-0177-z

10.Mascherini G, Petri C, Galanti G. Link between body cellular mass and left ventricular hypertrophy in female and male athletes. Journal of Sports Medicine and Physical Fitness. 2019; 59(1): 164-170. https://doi.org/10.23736/S0022-4707.18.08259-2 
11.Ramos-Jimenez A, Hernandez-Torres RP, Murguia-Romero M. Anthropometric equations for calculating body fat in young adults. Archivos Latinoamericanos de Nutricion. 2018; 68(2): 111-121.

12.Bacciotti S, Baxter-Jones A, Gaya A, Maia J. Body physique and proportionality of Brazilian female artistic gymnasts. Journal of Sports Sciences, 2018;36:749-56. https://doi.org/10.1080/02640414.2017.1340655

13. Chula de Castro JA, de Lima TR, Santos Silva DA. Body composition estimation in children and adolescents by bioelectrical impedance analysis: Asystematic review. Journal of Bodywork and Movement Therapies. 2018; 22(1): 134-146. https://doi.org/10.1016/j.jbmt.2017.04.010

14.International Standards for Anthropometric Assessment, ISAK. 2001.

15. Rovnaya OA, Podrigalo LV, Aghyppo OY, Cieślicka M, Stankiewicz B. Study of Functional Potentials of Different Portsmanship Level Synchronous Swimming Sportswomen under Impact of Hypoxia. Research Journal of Pharmaceutical Biological and Chemical Sciences. 2016; 7(4):1210-1219.

16. Volodchenko OA, Podrigalo LV, Iermakov SS, Żychowska MT, Jagiełło W. The Usefulness of Performing Biochemical Tests in the Saliva of Kickboxing Athletes in the Dynamic of Training. BioMed Research International, 2019;2019:1-7. https://doi.org/10.1155/2019/2014347

17.Podrigalo L, Iermakov S, Romanenko V, Rovnaya O, Tropin Y, Goloha V, Halashko O. Psychophysiological features of athletes practicing different styles of martial arts - the comparative analysis. International Journal of Applied Exercise Physiology, 2019;8(1):84-91. https://doi.org/10.30472/ijaep.v8i1.299

18. Romanenko V, Podrigalo L, Iermakov S, Rovnaya O, Tolstoplet E, Tropin Y, et al. Functional state of martial arts athletes during implementation process of controlled activity comparative analysis. Physical Activity Review, 2018;6:87-93. https://doi.org/10.16926/par.2018.06.12

19.de-Mateo-Silleras B, de-la-Cruz-Marcos S, Alonso-Izquierdo L,Camina-MartínMA,Marugán-de-MiguelsanzJM,Redondodel-Río MP. Bioelectrical impedance vector analysis in obese and overweight children. Plos One, 2019;14:e211148. https://doi.org/10.1371/journal.pone.0211148.

20.Tinsley GM, Graybeal AJ, Moore ML, Nickerson BS. Fat-free Mass Characteristics of Muscular Physique Athletes: Medicine \& Science in Sports \& Exercise 2018:1. https://doi.org/10.1249/MSS.0000000000001749
21.Branco BHM, Bernuci MP, Marques DC, Carvalho IZ, Barrero CAL, Oliveira FM de, et al. Proposal of a normative table for body fat percentages of Brazilian young adults through bioimpedanciometry. Journal of Exercise Rehabilitation, 2018;14:974-9. https://doi.org/10.12965/jer.1836400.200

22.van Rassel CR, Bewski NA, O'loughlin EK, Wright A, Scheel DP, Puig L, et al. Validity of electrical impedance myography to estimate percent body fat: comparison to bio-electrical impedance and dual-energy X-ray absorptiometry. The Journal of Sports Medicine and Physical Fitness, 2019;59. https://doi.org/10.23736/S0022-4707.18.08505-5

23.de-Mateo-Silleras B, Camina-Martín MA, de-FrutosAllas JM, de-la-Cruz-Marcos S, Carreño-Enciso L, Redondo-del-Río MP. Bioimpedance analysis as an indicator of muscle mass and strength in a group of elderly subjects. Experimental Gerontology, 2018;113:113-9. https://doi.org/10.1016/j.exger.2018.09.025

24.Filatova OV, Voronina IYu. Study of the human body composition by means of various bioimpedance analysis methods. Ukrainian Journal of Ecology. 2018; 8(4): 390392.

25. Araujo MLD, Andrade MLS de Souza, Prado LV da Silva. Accuracy of the BMI in diagnosing the excess body fat evaluated by electricalbioimpedance in university students. Nutricion Clinica y Dietetica Hospitalaria. 2018; 38(3): 154160.

26.Girsh YV, Gerasimchik OA. The role and place of bioimpedance analysis assessment of body composition of children and adolescents with different body mass. Byulleten Sibirskoy Meditsiny. 2018; 17(2): 121-132. https://doi.org/10.20538/1682-0363-2018-2-121-132

27.Campa F, Toselli S. Bioimpedance Vector Analysis of Elite, Subelite, and Low-Level Male Volleyball Players. International Journal of Sports Physiology and Performance. 2018; 13(9): 1250- 1253. https://doi.org/10.1123/ijspp.2018-0039

28.Chatindiara I, Williams V, Sycamore E, Richter M, Allen $\mathrm{J}$, Wham C. Associations between nutrition risk status, body composition and physical performance among community-dwelling older adults. Australian and New Zealand Journal of Public Health, 2019;43:56-62. https://doi.org/10.1111/1753-6405.12848

29.Fedewa MV, Nickerson BS, Esco MR. Associations of body adiposity index, waist circumference, and body mass index in young adults. Clinical Nutrition. 2019; 38(2):715-720. https://doi.org/10.1016/j.clnu.2018.03 


\section{Information about the authors:}

Podrigalo L.V.; (Corresponding author); http://orcid.org/0000-0002-7893-524X; I.podrigalo@mail.ru; Kharkov State Academy of Physical Culture; Klochkovskaya str. 99, Kharkov, 61022, Ukraine.

Artemieva H.P.; http://orcid.org/0000-0002-6965-4972; galina9767@gmail.com; Kharkov State Academy of Physical Culture; Klochkovskaya str. 99, Kharkov, 61022, Ukraine.

Rovnaya O.A.; http://orcid.org/0000-0003-1519-5632; rovnayaolga77@ukr.net; Kharkov State Academy of Physical Culture; Klochkovskaya str. 99, Kharkov, 61022, Ukraine.

Misevra N. S.; http://orcid.org/0000-0002-0476-3211; natali.misevra@gmail.com; Kharkov State Academy of Physical Culture; Klochkovskaya str. 99, Kharkov, 61022, Ukraine.

Sotnikova-Meleshkina Zh.V.; http://orcid.org/0000-0001-5534-8264; zhanna.univer@gmail.com; V. N. Karazin Kharkov National University; 4 Svobody Sq.,Kharkov, 61022, Ukraine.

Podavalenko A.P.; http://orcid.org/0000-0003-4585-060X; alekontp@ukr.net; Kharkiv Medical Academy of Postgraduate Education; Amosova str. 58, Kharkov, 61059, Ukraine.

Sokol K.M.; http://orcid.org/0000-0001-8363-8402; sokol_km@ukr.net; Kharkov National Medical University; Nauky Avenue, 4, Kharkov, 61022, Ukraine.

Robak I.Yu.; http://orcid.org/ 0000-0002-4837-4058; robak@ukr.net; Kharkov National Medical University; Nauky Avenue, 4, Kharkov, 61022, Ukraine.

Cite this article as:

Podrigalo LV, Artemieva HP, Rovnaya OA, Misevra NS, Sotnikova-Meleshkina ZhV, Podavalenko AP, Sokol KM, Robak IYu. Features of physical development and somatotype of girls and women involved in fitness. Pedagogics, psychology, medicalbiological problems of physical training and sports, 2019;23(4):189-195. https://doi.org/10.15561/18189172.2019.0405

This is an Open Access article distributed under the terms of the Creative Commons Attribution License, which permits unrestricted use, distribution, and reproduction in any medium, provided the original work is properly cited (http://creativecommons.org/licenses/by/4.0/deed.en).

Received: 14.05.2019

Accepted: 18.06.2019; Published: 29.08.2019 